\title{
openheart Day case complex devices: the state of the UK
}

\author{
Michael Waight, ${ }^{1}$ Abdula Elawady, ${ }^{1}$ Heather Gage, ${ }^{2}$ Morro Touray, ${ }^{2}$ \\ Shaumik Adhya ${ }^{1}$
}

To cite: Waight M, Elawady A, Gage $\mathrm{H}$, et al. Day case complex devices: the state of the UK Open Heart 2019;6:e001023. doi:10.1136/ openhrt-2019-001023

Received 31 January 2019 Revised 13 March 2019 Accepted 25 March 2019
Check for updates

(c) Author(s) (or their employer(s)) 2019. Re-use permitted under CC BY-NC. No commercial re-use. See rights and permissions. Published by BMJ.

${ }^{1}$ Cardiology, Medway Maritime Hospital, Gillingham, UK

${ }^{2}$ Department of Health

Economics, University of Surrey, Guildford, UK

Correspondence to Dr Michael Waight; michaelwaight@nhs.net

\section{ABSTRACT}

Objective Complex cardiac devices including implantable cardioverter defibrillator (ICD) and cardiac resynchronisation therapy (CRT) devices can safely be implanted as a day case procedure as opposed to overnight stay. We assess how common day case complex device therapy is and the cost implications of more widespread adoption across the UK.

Methods A freedom of information request was sent to all centres performing complex cardiac devices across the UK to assess the adoption of this technique. Cost implications were assessed using Department of Health National Schedule of Reference Costs 2016-2017.

Results 100 UK centres were surveyed, 80\% replied. Eighty per cent of UK centres already implant complex cardiac devices as a day case to some extent. $64.06 \%$ of centres have a protocol for this. $12.82 \%$ of centres do $<25 \%$ of complex devices as a day case. $15.38 \%$ do $25 \%-50 \%$ as day case. $17.95 \%$ do $50 \%-75 \%$ as day case and $33.33 \%$ do $>75 \%$ as day case. There was no relationship between centre volume and the proportion of devices done as a day case as opposed to overnight stay. The cost saving of performing a complex device as a day case as opposed to overnight stay was $£ 412$ per ICD, £525 per CRT-pacemaker and £2169 per CRT-defibrillator. Conclusions Day case complex devices are already widespread across the UK, however, there is scope for increase. An increase in proportion of day case devices could translate to $£ 5583265$ in savings annually for the National Health Service if all centres performed $75 \%$ of devices as a day case.

\section{INTRODUCTION}

Simple permanent pacemakers have been implanted as day case procedures since the early $1980 \mathrm{~s},{ }^{1}$ with the first UK day case pacemaker being performed in $1989 .^{2}$ Cost benefit studies have shown savings with same-day discharge compared with traditional overnight stay of between $£ 203$ and $£ 430$ per patient ${ }^{34}$. More recently, various centres have reported success in performing complex cardiac devices including implantable cardioverter defibrillator (ICD) and cardiac resynchronisation therapy (CRT) as day cases, including improvements in patient satisfaction ${ }^{5}$ without compromising safety. ${ }^{5-8}$ These recent studies suggest that same-day discharge is becoming

\section{Key questions}

What is already known about this subject?

- Day case complex cardiac devices have been shown to be safe and are associated with increased patient satisfaction compared with overnight stay. Other medical fields have demonstrated cost savings when moving from overnight stay procedures to day case. Single-centre studies demonstrate that complex cardiac devices are already being implanted in some centres.

What does this study add?

- This study demonstrates that the majority of hospitals already implant complex cardiac devices as a day case to some extent. However, less than half of all patients having a complex cardiac device currently have this done as a day case procedure. There are significant cost savings to be made if a higher proportion of complex cardiac devices were implanted as a day case.

How might this impact on clinical practice?

- This sheds light on the current state of clinical practice in the UK and provides impetus to those centres which do not yet implant these devices as a day case. This study may encourage more day case procedures to be undertaken due to the resulting cost savings of up to $£ 2169$ per device compared with overnight stay.

more widespread and increasingly seen as the standard of care, even though it is not advocated in the current guidelines on complex cardiac devices. Here, we assess the situation across the UK with regard to same-day discharge following complex cardiac device insertion and examine the cost implications if these were to become routine practice across the country.

\section{METHODS}

In order to assess the current UK-wide practice for complex cardiac device insertion, a list of all UK centres which implant cardiac devices was generated from the National Institute for Cardiovascular Outcomes Research (NICOR) National Audit of Cardiac Rhythm 
Management Devices ${ }^{9}$ from 2015 to 2016. This includes both National Health Service (NHS) and private centres. Centres that do not implant complex devices, or those that implant less than 20 complex devices per year as well as paediatric centres, were excluded. A survey was sent to all remaining UK centres which perform complex cardiac devices as per the Freedom of Information Act, 2000.

The survey was comprised of the following questions:

1. Does your hospital perform complex cardiac devices as a day case procedure? This includes ICD, CRTpacemaker and defibrillator (CRT-P and CRT-D).

2. If so, do you have a trust protocol for this procedure?

3. What proportion of complex pacing is done as day case as compared with overnight stay: $<25 \%$ day case, $25 \%-50 \%$ day case, $50 \%-75 \%$ day case or $>75 \%$ day case?

We assessed the costs of implanting each of the three different devices (ICD, CRT-P and CRT-D) when performed as both day case as well as with an inpatient stay. These data were obtained by using the Department of Health National Schedule of Reference Costs 2016-2017. ${ }^{10}$ We opted for this as it is a more representative estimation of the true cost of the procedures to the NHS, rather than a tariff, which would be the amount paid to a trust by the government on insertion of a device. The reference cost data give an upper and lower quartile price as well as the national average. We used the national average in all cases. This data allowed us to compare the cost difference between an inpatient stay and a day case procedure. Statistical analysis of differences between responses was assessed using the $\chi^{2}$ test.

\section{RESULTS}

Of the 198 centres identified from the NICOR audit, 64 were excluded as they do not perform complex cardiac devices $(n=60)$ or were paediatric centres $(n=4)$. A further 34 centres were excluded as they implant less than 20 complex cardiac devices per year. We sent the survey to the remaining 100 centres. Of these 100 centres, the number of complex devices inserted per year ranged from 20 to 639 with a mean of 135 . The centres are shown below in by volume according to the NICOR audit as well as their responses to our survey (figure 1). ${ }^{9}$

Of the surveyed centres, we received responses to the freedom of information (FOI) requests from $80(80 \%)$ of the 100 centres. Sixty-four centres $(64 \%)$ stated that they already implant complex cardiac devices as a day case: $41(41 \%)$ centres perform complex pacing as a day case and have a protocol for the procedure as part of the trust policy. Twenty-three (23\%) centres perform complex pacing as day case but do not have a protocol for this (figure 2).

When asked what proportion of their complex devices are done as a day case as compared with overnight stay, two centres were unable to give this information. These were excluded for further evaluation. The proportion of complex devices done as a day case from the remaining centres was as follows. Sixteen centres $(20.51 \%)$ do not perform any complex devices as a day case. Ten centres $(12.82 \%)$ do $<25 \%$ as day case. Twelve centres $(15.38 \%)$ do $25 \%-50 \%$ as day case. Fourteen centres (17.95\%) do $50 \%-75 \%$ as day case and 26 centres $(33.33 \%)$ do $>75 \%$ as day case (figure 3 )

We analysed the total number complex devices that these respective quintiles implant per year; those doing $<25 \%$ as day case implant 1492 . Those doing $25 \%-50 \%$ implant 1922. Those doing 50\%-75\% implant 2316 and those doing $>75 \%$ as day case implant 3582 per year. Additionally, those centres which do not do any complex

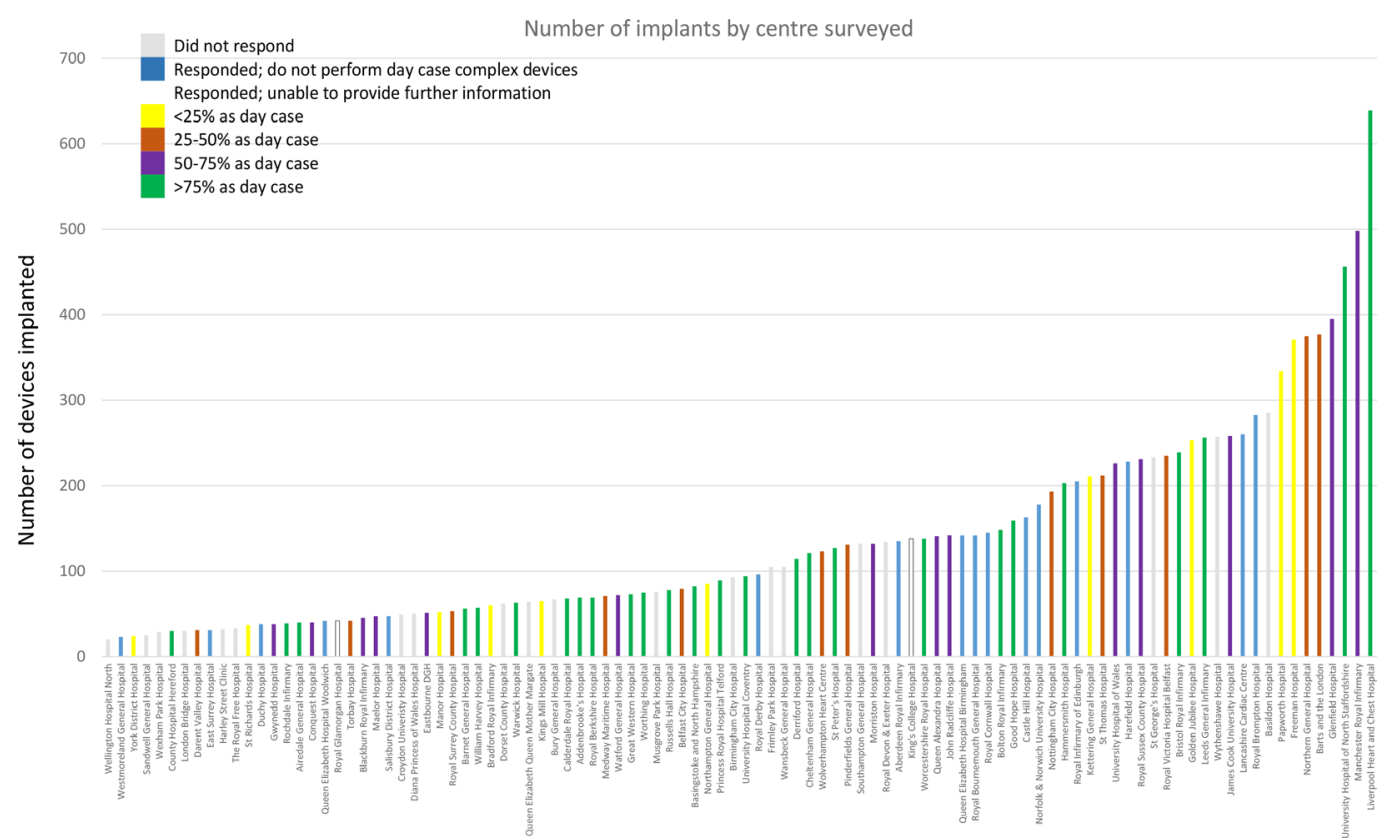

Figure 1 Number of devices implanted by the centres we surveyed per year as of APRIL 2015 to March 2016 and their respective responses to FOI survey. Data from NICOR audit $2016 .{ }^{9}$ FOI, freedom of information. 


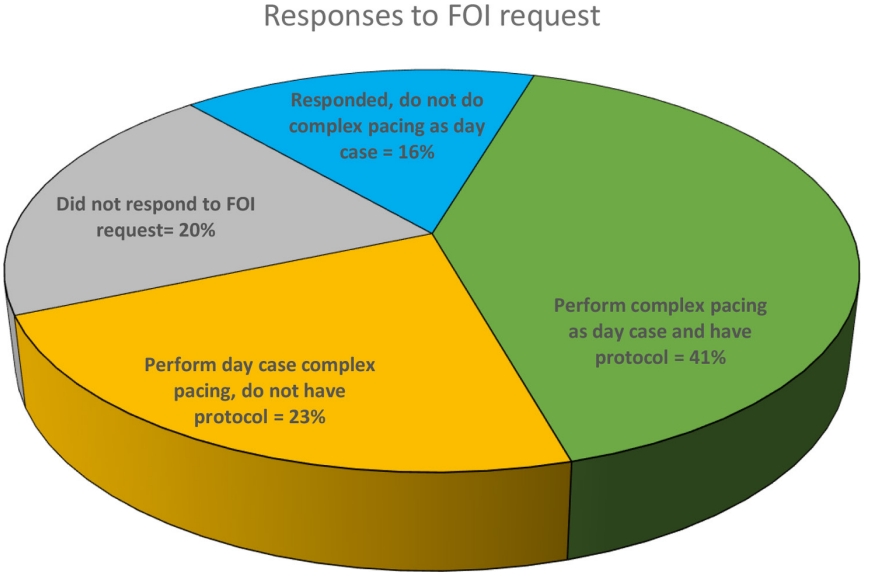

Figure 2 Proportion of centres which responded to FOI Request, and how many perform complex pacing as a day case and have a protocol. FOI, freedom of information.

devices as a day case amount to 2158 devices per year (figure 4).

To investigate the relationship between centre volume and the proportion of devices implanted as a day case, we divided the centres into quartiles by number of complex devices inserted annually-Q1 ( $<50$ devices per year), Q2 (51-93 devices per year), Q3 (94-193 devices per year) and Q4 (>193 devices per year). The results of this are demonstrated below in figure 5 . There was no difference in proportion of day case devices versus overnight devices between the different volume centres.

Although not included in the questionnaire, three centres were able to give a breakdown of the proportion of each complex device (ICD, CRT-P and CRT-D) which are implanted as a day case. On average, $75 \%$ of ICDs, $30 \%$ of CRT-P devices and 25\% of CRT-D devices are implanted as a day case in these centres (figure 6).
We looked at the cost difference between complex cardiac devices which are inserted as a day case as compared with an overnight stay. Table 1 demonstrates the national reference costs for these, including ICD, CRT-P and CRT-D. ${ }^{10}$ The saving associated with a day case procedure as opposed to an overnight stay is demonstrated on the right of the table.

\section{DISCUSSION}

As a practice, day case complex cardiac devices are already widespread across the UK, but to varying degrees. Eighty per cent of centres which responded to our FOI request already perform day case complex cardiac devices to some extent. Where centres do perform complex devices as a day case, there is a trend towards doing a high proportion of all devices as a day case rather than an overnight stay. However, based on responses, as a total proportion of all complex devices inserted in the UK, less than half are currently being implanted as a day case. There does not seem to be any relationship between the volume of complex devices inserted annually and the proportion which are done as a day case, that is, high volume centres do not particularly seem to be performing a large number of day case procedures.

There are great potential savings to be made in switching from overnight procedures to day case. This has been demonstrated in many fields of medical practice, with a strong evidence base, particularly in the surgical specialties. ${ }^{11-13}$ Day case complex cardiac devices can save between $£ 412$ (for ICD) and £2169 (CRT-D) per device. From our data, we can estimate the total proportion of complex devices which are implanted as a day case in the UK from the centres surveyed. Assuming that each centre does half the quartile range as a day case procedure (ie, $12.5 \%$ for those doing $<25 \%$ as day case, $37.5 \%$ for those

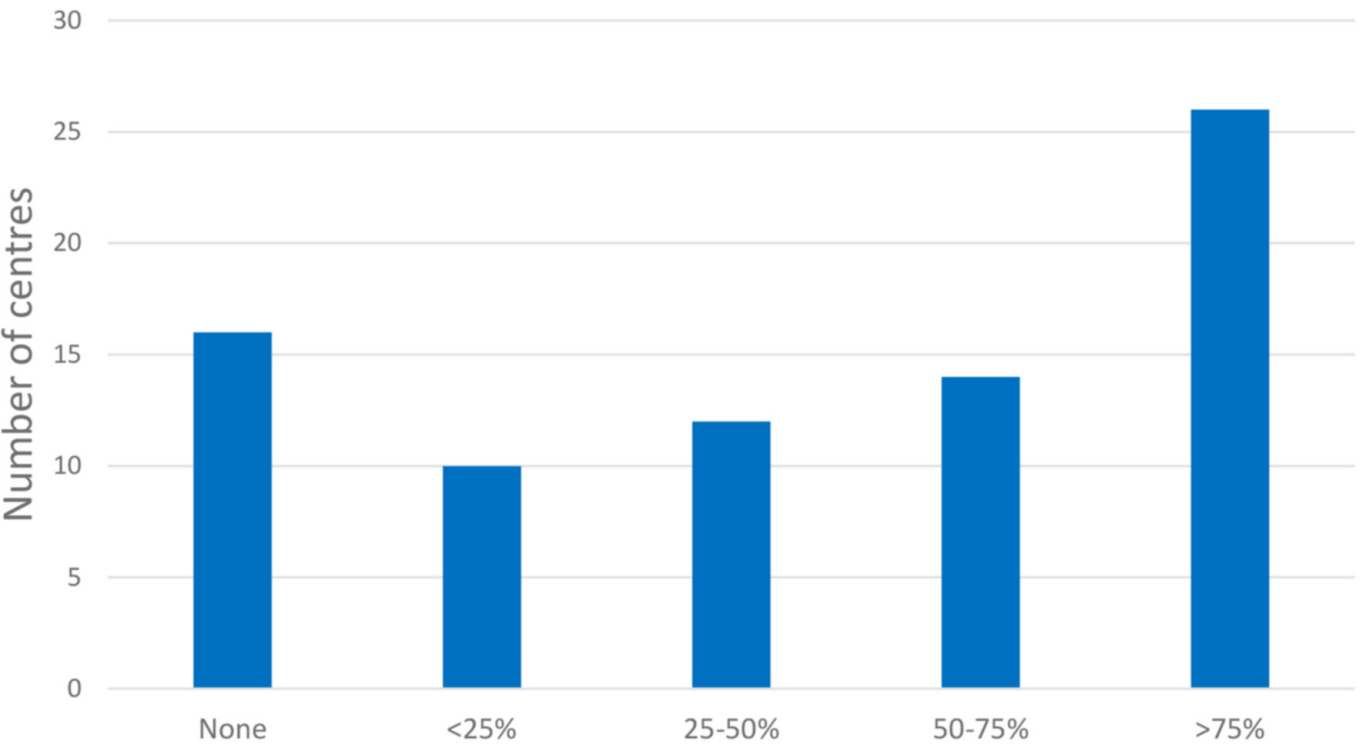

Proportion of devices done as day case

Figure 3 Proportion of complex devices done as day case. 
4000

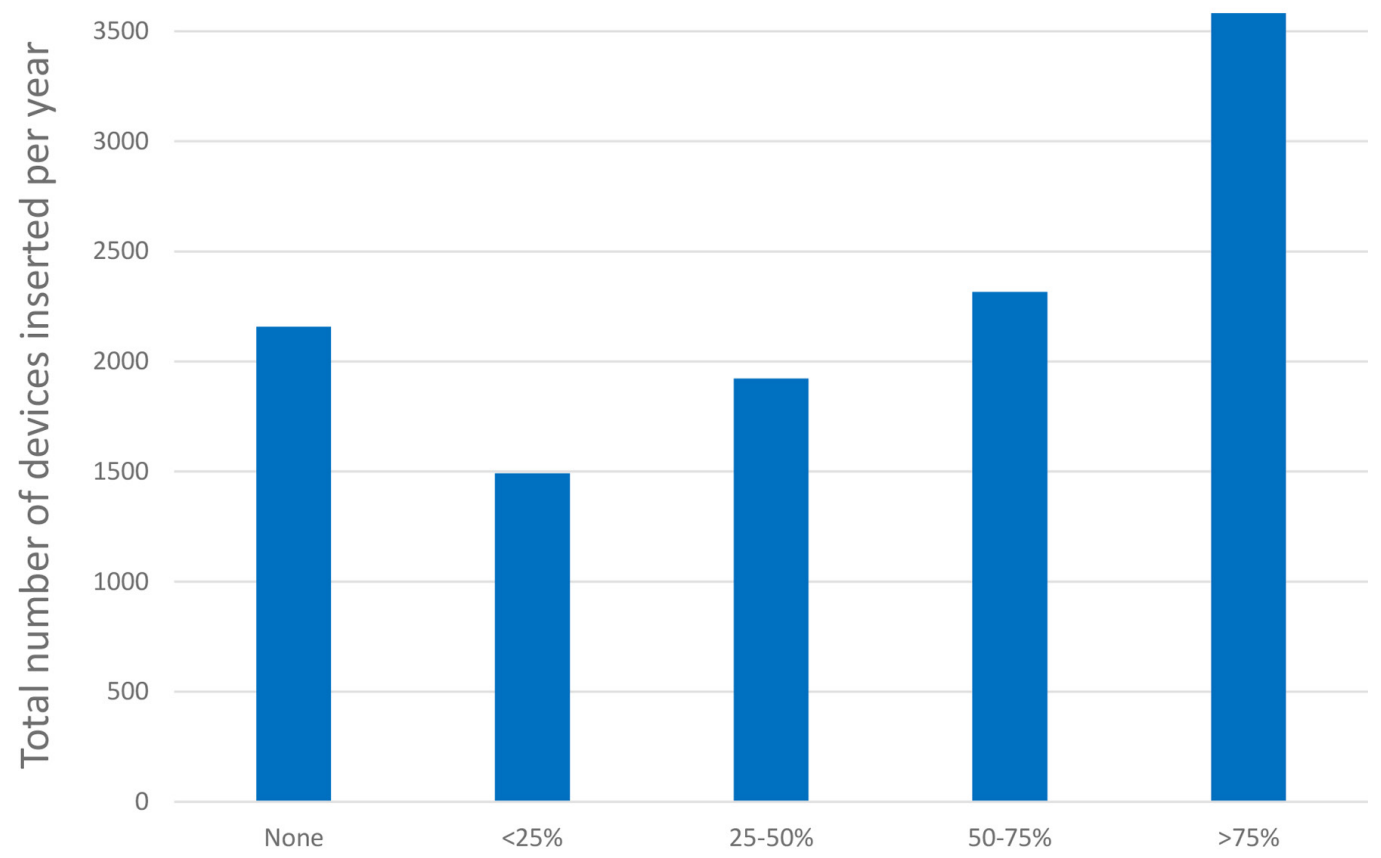

Proportion of complex devices done as day case

Figure 4 Total number of complex devices inserted per year by proportion done as day case.

doing $25 \%-50 \%$, etc), $47.86 \%$ of all complex cardiac devices are being inserted as a day case annually in the UK. Every year the European Heart Rhythm Association produces a document called 'The White Book' which surveys and records the total number of complex cardiac devices inserted annually in each European Society of
Cardiology member country. ${ }^{14}$ In the UK, in 2016, there were 7242 ICD insertions, 4318 CRT-P insertions and 7063 CRT-D insertions in total, ${ }^{14}$ making a total of 18 623 complex devices inserted per year. If the proportion of devices being implanted as a day case increased from the current $47.86 \%$ so that each centre was achieving

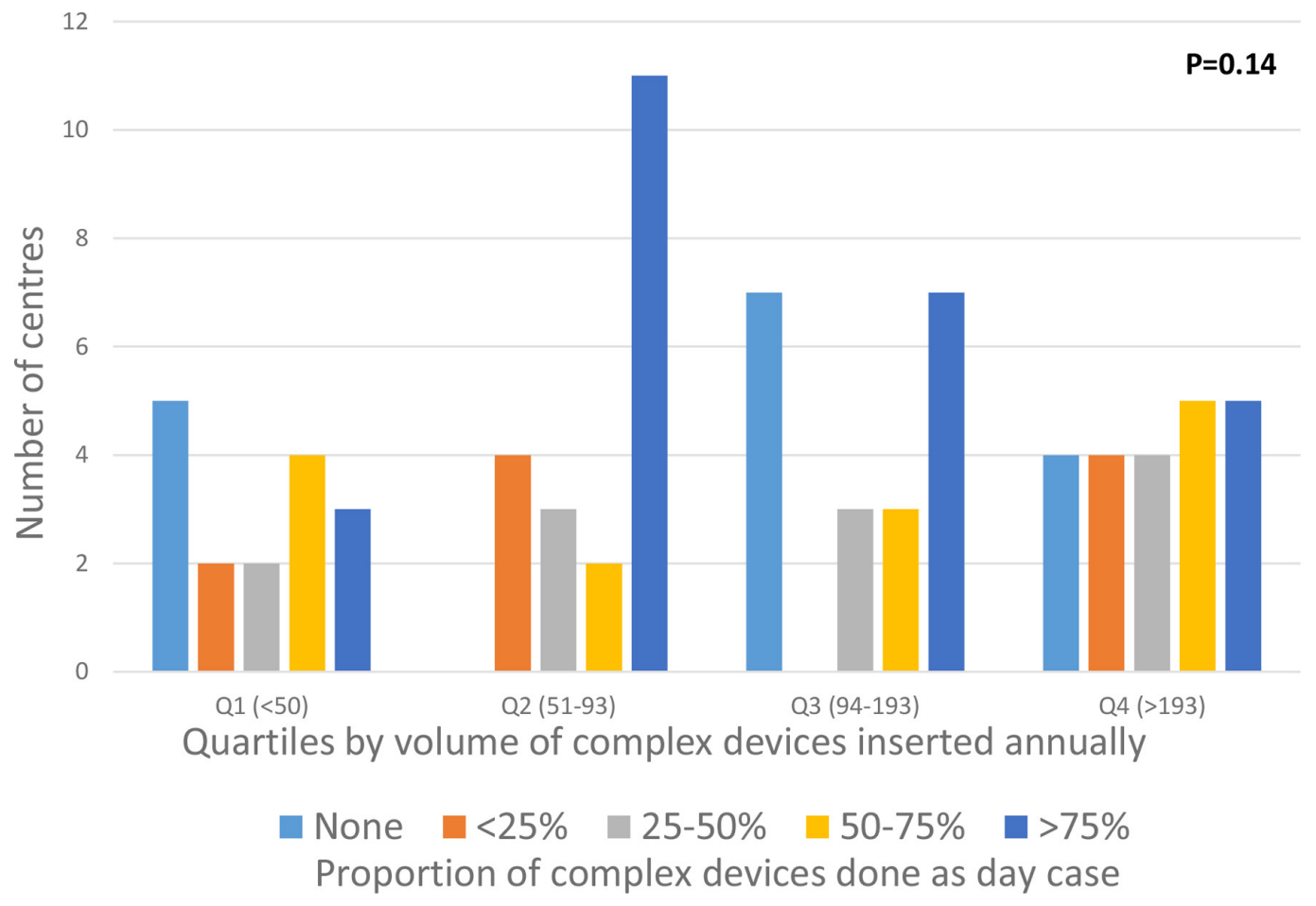

Figure 5 Proportion of devices inserted as day case by volume of centre. 

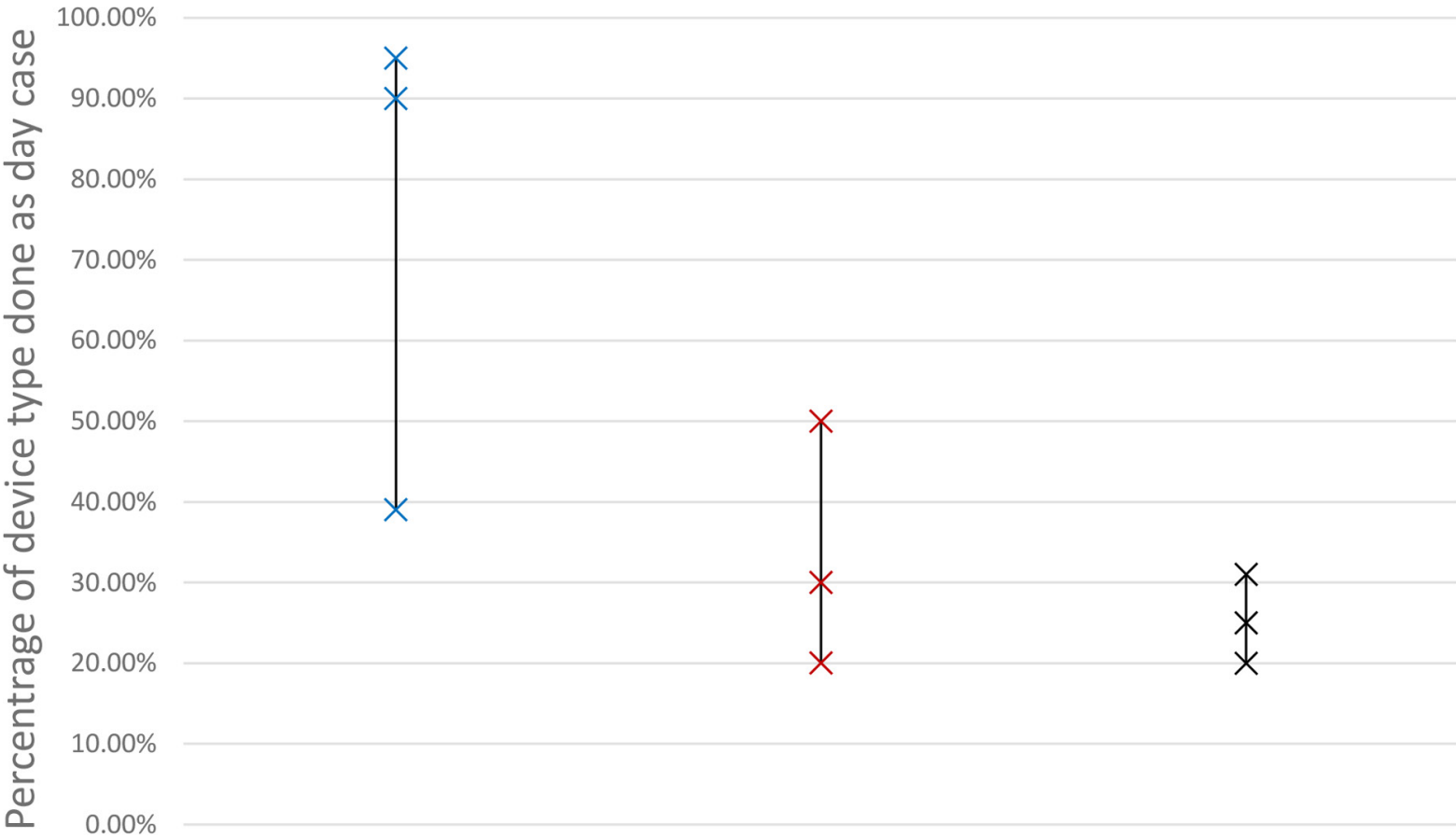

ICD

CRT-P

CRT-D

\section{Device Type}

Figure 6 Proportion of each type of complex device inserted as a day case $(n=3)$. CRT-D, cardiac resynchronisation therapydefibrillator; CRT-P, cardiac resynchronisation therapy-pacemaker; ICD, implantable cardioverter defibrillator.

the highest quartile ( $75 \%$ as day case), then this would change the total number of devices being inserted as a day case from 8913 to 13967 or an extra 5054 devices per year. Given the current split between the three complex devices, this would equate to a saving of $£ 5583265$ per year across the UK (table 2). It would likely also improve the patient experience and freeing up beds for other patients.

This study has some limitations which should be addressed in combination with its conclusions. We used an FOI request to gain data around the current state of day case complex devices across the UK at present. This limited the detail of the questions asked in order to reduce the time centres required to formulate a response. Furthermore, there was a significant non-response rate. Non-responders were contacted at serial points throughout the study and the final non-responder

Table 1 Costs of implanting complex devices as day case, overnight stay and day case saving ${ }^{10}$

\begin{tabular}{llll}
\hline Procedure & Day case & Overnight & $\begin{array}{l}\text { Day case } \\
\text { saving }\end{array}$ \\
\hline ICD & $£ 4792$ & $£ 5204$ & $£ 412$ \\
CRT-P & $£ 3622$ & $£ 4147$ & $£ 525$ \\
CRT-D & $£ 6530$ & $£ 8699$ & $£ 2169$ \\
\hline
\end{tabular}

CRT-D, cardiac resynchronisation therapy-defibrillator; CRT-P, cardiac resynchronisation therapy-pacemaker; ICD, implantable cardioverter defibrillator. rate was $20 \%$. Non-responding centres did not appear to be different from responders in terms of volume of complex devices done per year, therefore, this is unlikely to be a major factor.

The data include feedback from private hospitals, which were not obliged to respond to the FOI request and also are not reimbursed in the same way that the NHS centres are, therefore, our results are only applicable to the NHS. Also, there is inherent error in assuming the midpoint of the quartile range to estimate the number of devices implanted as a day case per year. Another issue is the limited feedback on the split between ICD, CRT-P and CRT-D as daycase procedures. A small number of centres were able to give us this information and as expected, the greater the complexity of the procedure, the more likely it was to be done as an overnight stay with three quarters of ICDs but only one-quarter of CRT-D devices being inserted as a day case procedure. It is possible that if certain centres implant more ICDs compared with CRT devices, this may partly explain the discrepancy in day case proportions between centres.

Potential barriers to more widespread application of day case complex cardiac devices include the following. Some cardiologists may feel that a day case complex device is less safe than when a patient can be observed overnight or associated with a higher readmission rate. This has been shown not to be the case with several papers demonstrating no increase in complications with same-day discharge of patients having complex cardiac 


\begin{tabular}{|c|c|c|c|c|c|c|}
\hline Procedure & $\begin{array}{l}\text { Number per } \\
\text { year }\end{array}$ & $\begin{array}{l}\text { Current daycase } \\
(47.86 \%)\end{array}$ & $\begin{array}{l}\text { Ideal target } \\
(75 \%)\end{array}$ & $\begin{array}{l}\text { Extra devices } \\
\text { per year }\end{array}$ & $\begin{array}{l}\text { Saving per } \\
\text { device }\end{array}$ & $\begin{array}{l}\text { Total saving per } \\
\text { year }\end{array}$ \\
\hline ICD & 7242 & 3466 & 5432 & 1966 & $£ 412$ & $£ 809992$ \\
\hline CRT-P & 4318 & 2067 & 3239 & 1172 & $£ 525$ & $£ 615300$ \\
\hline CRT-D & 7063 & 3380 & 5297 & 1917 & $£ 2169$ & $£ 4157973$ \\
\hline Total & & & & & & $£ 5583265$ \\
\hline
\end{tabular}

CRT-D, cardiac resynchronisation therapy-defibrillator; CRT-P, cardiac resynchronisation therapy-pacemaker; ICD, implantable cardioverter defibrillator.

devices over a 6 -week follow-up period. ${ }^{5} 15$ These papers are single-centre experiences, however, it is difficult to envisage how complication rates would vary significantly across the country. Some patients may not like the idea of being discharged after a complex procedure such as a CRT-D. However, it has been shown that same-day discharge following CRT is associated with higher satisfaction from patients compared with overnight stay. ${ }^{5}$

Widespread adoption of day case as the standard of care for insertion of complex devices will have implications of list organisation and will require a defined protocol in order to ensure patient safety and efficiency. In our study, $66 \%$ of centres performing day case complex devices had a protocol. We received an example protocol from three of the surveyed hospitals. There was discrepancy between these protocols in terms of the timing of the postimplant chest X-ray and device check and also the duration of observation prior to discharge-varying from 90 min to 4 hours postprocedure. An example of the protocol created at our trust is included in supplement A. Predischarge protocol includes a device check as well as a chest X-ray to assess lead position and, in the case of axillary or subclavian access, exclusion of pneumothorax. These need to be performed in time for them to be appropriately checked and the patient discharged. This means that it is likely that patients undergoing day case complex devices will need to be done earlier in the day than had they been planned for an overnight stay. A potential solution to this is using cephalic-only access as has been reported to be safe and effective. ${ }^{1617}$

On the whole, overcoming these barriers is a surmountable challenge that should lead to both clinical and financial benefit in the field of complex devices.

Contributors MW: primary data collector, data analyser and author. Responsible for overall content. AE: secondary data collector and data analyser. MT: support with health economics data and calculation of cost savings. HG: support with health economics data and calculation of cost savings. SA: project instigator and supervisor. Edited manuscript and assisted with conclusions. Responsible for overall content.

Funding The authors have not declared a specific grant for this research from any funding agency in the public, commercial or not-for-profit sectors.

Competing interests None declared.

Patient consent for publication Not required.

Provenance and peer review Not commissioned; externally peer reviewed.

Data availability statement No additional data are available.
Open access This is an open access article distributed in accordance with the Creative Commons Attribution Non Commercial (CC BY-NC 4.0) license, which permits others to distribute, remix, adapt, build upon this work non-commercially, and license their derivative works on different terms, provided the original work is properly cited, appropriate credit is given, any changes made indicated, and the use is non-commercial. See: http://creativecommons.org/licenses/by-nc/4.0/.

\section{REFERENCES}

1. Zegelman M, Kreuzer J, Wagner R. Ambulatory pacemaker Surgery-Medical and economical advantages. Pacing Clin Electro 1986;9:1299-303.

2. Haywood GA, Camm AJ, Ward DE. Insertion of permanent pacemakers as a day case procedure. BMJ 1989;299:1139.

3. Haywood GUYA, Jones SUEM, Camm AJ, et al. Day case permanent pacing. Pacing Clin Electro 1991;14:773-7.

4. Osman F, Krishnamoorthy S, Nadir A, et al. Safety and costeffectiveness of same day permanent pacemaker implantation. Am J Cardiol 2010;106:383-5.

5. Ahmed N, Sun P, Rajagopalan U, et al. 74 Safety and Feasibility of Day Case Cardiac Resynchronization Therapy Implantation A Single Tertiary Centre Experience: Abstract 74 Table 1. Heart 2015;101(Suppl 4):A40.2-A41.

6. Nelson TA, Bhakta A, Lee J, et al. Evaluation of a new same-day discharge protocol for simple and complex pacing procedures. British Journal of Cardiology 2016;23:114-8.

7. Atherton G, McAloon CJ, Chohan B, et al. Safety and costeffectiveness of same-day cardiac resynchronization therapy and implantable cardioverter Defibrillator implantation. Am J Cardiol 2016;117:1488-93.

8. Darda S, Khouri Y, Gorges R. Al Samara M Jain S, Daccarett M, Machado C, feasibility and safety of same-day discharge after implantable cardioverter defibrillator placement for primary prevention. PACE 2013;36); :885-91.

9. National Audit Of Cardiac Rhythm Management Devices, 2016. Available: http://www.ucl.ac.uk/nicor/nicor-news-publication/nicorcrm-devices-report-2014-15

10. Department of Health. Reference Cost Collection: National Schedule of Reference Costs, 2016-17 - NHS trusts and NHS foundation trusts. Department of Health, London, 2017. Available: https:// improvement.nhs.uk/resources/reference-costs/\#rc1718 [Accessed 7 Jun 2018].

11. Huang A, Ryu J-J, Dervin G. Cost savings of outpatient versus standard inpatient total knee arthroplasty. Can J Surg 2017;60:57-62.

12. Crawfod D, Li C, Sprague S, et al. Clinical and cost implications of inpatient versus outpatient orthopaedic surgeries: a systematic review of the published literature. Orthop Rev 2015;7.

13. Gurusamy K, Junnarkar S, Farouk M, et al. Day-case versus overnight stay for laparoscopic cholecystectomy. Cochrane Database Syst Rev 2008;16.

14. Hindricks G, Camm J, Merlely B. The EHRA white book 2017 , the current status of cardiac electrophysiology in ESC member countries, 2017. Available: https://www.escardio.org/static_file/ Escardio/Subspecialty/EHRA/Publications/Documents/2017/ehrawhite-book-2017.pdf [Accessed 9 Oct 2019].

15. Nelson K, Welsh S, Batty J, et al. 53 Timing of Cardiac Rhythm Management Device Complications: Is Day Case Implantation Safe? Heart 2016;102(Suppl 6):A38-A39.

16. Hadjis A, Proietti R, Essebag V. Implantation of cardiac resynchronization therapy devices using three leads by cephalic vein dissection approach. Europace 2017;19:1514-20. 
